\title{
Clinical features and risk factors for upper gastrointestinal bleeding in children: a case-crossover study
}

\author{
Lamiae Grimaldi-Bensouda • Lucien Abenhaim • Laurent Michaud • \\ Olivier Mouterde • Annie Pierre Jonville-Béra • Bruno Giraudeau • Benoît David • \\ Elisabeth Autret-Leca
}

Received: 18 February 2010 /Accepted: 21 April 2010/Published online: 16 May 2010

(C) Springer-Verlag 2010

\begin{abstract}
Objective This population-based survey was conducted to provide a formal description of upper gastrointestinal bleeding (UGIB) in children on a nationwide basis and assess the contribution of risk factors, principally nonsteroidal anti-inflammatory drugs (NSAID).

Methods A case-crossover study of UGIB patients aged between 2 months and 16 years was conducted in France. Medical data were collected by physicians, and personal risk factors and exposure to drugs during the month preceding the onset of the bleeding was ascertained by a standardised telephone interview with parents. The odds ratios for UGIB and NSAID was assessed by comparing exposure during the 7 days preceding the date of hospitalisation and the 21 st to the 28 th days before that date.
\end{abstract}

L. Grimaldi-Bensouda $\cdot$ L. Abenhaim

Inserm U657 "Pharmacoepidemiology Unit",

Paris, France

L. Grimaldi-Bensouda $\cdot$ B. David

LA-SER, alpha network, Pepiniere Paris Sante Cochin,

29 rue du Faubourg Saint-Jacques,

75014 Paris, France

L. Abenhaim

London School of Hygiene and Tropical Medicine,

London, UK

L. Michaud

Department of Paediatric Gastroenterology,

Jeanne de Flandre Hospital, France,

Avenue Eugène Avinée,

59037 Lille Cedex, France

O. Mouterde

Department of Paediatrics, Rouen University Hospital, France,

1 rue de Germont,

76031 Rouen Cedex, France
Results A total of 177 children with UGIB were included over 2 years. Eighty-three children had taken at least one NSAID before the index date, among which 58 were ibuprofen, 26 aspirin and nine others. The adjusted odds ratio (OR) of exposure was 8.2 [95\% confidence interval (CI) 2.626.0] for NSAIDs altogether, and this was 10.0 (95\% CI 2.0 51.0) for ibuprofen and 7.3 (95\% CI 0.9-59.4) for aspirin. There was no increased risk associated with NSAIDS for oesophageal lesion [OR $=1.0$ [(5\% CI:0.2-7.2)].

Conclusion The study confirms that UGIB is rare but that some cases may be avoided, as one third of the cases was attributable to exposure to NSAID at doses used for analgesic or antipyretic purposes, which may be attained with alternative therapy. The findings from this study call for more caution in prescribing NSAIDS to children.

A. P. Jonville-Béra $\cdot$ E. Autret-Leca

Department of Pharmacology, Tours University Hospital, France,

2 boulevard Tonnellé,

37044 Tours cedex 9, France

B. Giraudeau

Inserm CIC 202, France; François Rabelais University Tours,

France; Tours University Hospital, France,

2 bis boulevard Tonnellé,

37032 Tours cedex 1, France

E. Autret-Leca

Department of Pharmacology, François Rabelais University Tours, Tours, France

E. Autret-Leca $(\square)$

Service de Pharmacologie Clinique - CHRU de Tours,

2 boulevard Tonnelle,

37044 Tours cedex 9, France

e-mail: autret-leca@med.univ-tours.fr 
Keywords Upper gastrointestinal bleeding . Nonsteroidal anti-inflammatory drug $\cdot$ Children $\cdot$ Casecrossover - Ibuprofen

\section{Introduction}

Upper gastrointestinal bleeding (UGIB) is a rare but severe occurrence in children that often requires emergency treatment. It is generally agreed that the disease presents itself with haematemesis or maelena that it is favoured by a medical history of ulcer, coagulation disorders, portal hypertension and Mallory-Weiss syndrome and that aspirin and some other nonsteroidal anti-inflammatory drugs (NSAIDs) play a causative role [1-4]. Data pertaining to children are, however, limited [5], and the evidence is based mainly on case reports, series and relatively small cohorts [6-8]. The actual distribution of anatomical locations and lesion presentation and the part of the disease attributable to risk factors and drugs are poorly understood in children. The role of ibuprofen has been dismissed after a large randomised double-blind trial of febrile children treated by paracetamol or ibuprofen concluded there was no statistical difference in disease risk between the drugs [9]. However, the four cases of UGIB observed during the study were in the ibuprofen arm [9]. In clinical practice, the observation of patients exposed to this drug is relatively frequent, but the use of the drug is also extremely frequent. Thus, it is still questionable as to whether ibuprofen is or is not a risk factor for this disease, and if so, at what dosage. To our knowledge, no population-based study of drug risk factors and UGIB in children has been reported. We conducted this study to provide a formal description of the location and clinical presentation of UGIB in children and describe the relative contribution of several risk factors, including drugs. The study was powered with the primary objective of assessing the potential contribution of NSAIDs.

\section{Methods}

\section{Cases}

We conducted a national study in which paediatric gastroenterologists from all 32 university hospitals in France were identified and contacted. Twenty agreed to participate. Two large regional hospitals were subsequently added. Potential participants were informed of the study objectives, and when they agreed to participate, they were visited for study implementation. Patients to be recruited were children aged between 2 months and 16 years of both genders with UGIB defined as oesophageal and/or gastric and/or duodenal bleeding and presenting with haematemesis, maelena or haemorrhagic shock. Gastroenterologists were requested to report all cases identified in their centres during the study period and to describe clinical presentation using clinical research forms. Among the items of interest were previous medical history, symptoms and signs at presentation, diagnostic procedures applied, severity of the bleeding and treatment to manage UGIB. Physicians were required to describe endoscopy findings, if performed. A priori risk factors included portal hypertension, history of UGIB or gastric or duodenal ulcer, gastrooesophageal reflux and coagulation disorders. Consent was obtained by the physicians from the parent of participating children.

\section{Interviews}

Parents were given a self-assessment questionnaire by their child's physicians to fill out in preparation for the interview. Parents were questioned by two independent trained interviewers who contacted them at home by telephone and confirmed their consent. The interview was conducted in the 10 days following UGIB. Information on children's drug intake in the 4 weeks before hospitalisation for UGIB was requested, and parents were asked to have at hand the written prescriptions and drug packaging information. To minimize recall bias, parents were informed that drug use as far as 1 month prior to onset of bleeding was just as important as recent drug use. Parents were asked to report the drug(s) used by their children, without any list provided to them a priori. For each drug reported within the 4 weeks prior to hospitalisation, indication of use, dosage, duration of use and date of initiation were requested. Dosages were recorded as prescribed, usually in milligrams $(\mathrm{mg}) /$ kilogram $(\mathrm{kg})$ per day. Those reported in $\mathrm{mg} /$ day were converted to $\mathrm{mg} / \mathrm{kg}$ per day (three patients). Drugs were first coded as reported (usually brand or generic name) and then by class (antibiotics, antacids, NSAIDs, corticoids, others). We considered NSAIDs used at the time of the study (aspirin, ibuprofen, ketoprofen, mefenamic acid, fenamate, tiaprofenic acid) and the others. Paracetamol was coded individually. Drug exposure was defined by at least one drug intake during risk or control periods (described below).

\section{Sample size}

The study was powered to detect a hypothetical relative risk (RR) of NSAID-related UGIB of 3, with $95 \%$ confidence interval $(\mathrm{CI})$ and $80 \%$ power, assuming a prevalence of NSAID use in children of $4 \%$. The odds ratio (OR) of 3 was chosen because it is usually reported in adults treated with ibuprofen, the most frequently used NSAID in children [10]. The prevalence of NSAID use of $4 \%$ in the paediatric population was chosen assuming children are exposed 2 weeks per year to NSAIDs (personal data). A 
target sample size of 187 children with UGIB was calculated as required for such a goal. Thirty centres were initially thought to be necessary for the recruitment.

\section{Design}

A case-crossover comparison for the presence of transient risk factors was chosen for this study. In this design, cases are taken as their own controls [11] and exposures compared for different individual time windows considered as at risk or not at risk for developing the disease as a consequence of exposure. The predefined periods for comparisons were the 7 days preceding the date of hospitalisation (period at risk, or week 1) and the 21 st to the 28th days before that date (control period, or week 4).

\section{Statistical analysis}

Crude and adjusted case-crossover ORs were calculated for exposure to any NSAID during the risk or control periods. Crude ORs were estimated with methods for matched-pair studies, by $\mathrm{N}_{01} / \mathrm{N}_{10}$ (Mantel-Haenszel estimate for matched-pair analyses) where $\mathrm{N}_{01}$ is the number of cases exposed during the risk period and not the control period, and $\mathrm{N}_{10}$ the number of cases not exposed during the risk period and exposed during the control period [11]. Sets where exposures occurred in both periods were considered as concordant pairs. Potential confounders known to influence the disease (portal hypertension, history of UGIB or gastric or duodenal ulcer and coagulation disorders) were defined a priori. Children with and without those risk factors were compared regarding NSAID use. Multivariate conditional logistic regression was performed with all a priori confounders cited above. All NSAIDs and the three most used classes of drugs other than NSAIDs were included into the final model. Results are presented as means, percentages, and ORs with 95\% two-sided CI with beta set at $20 \%$. Statistical analysis and estimation of OR and their CI were performed using SAS software version 9.1 (SAS Institute, Inc., NC, USA). The fraction of cases attributable to an exposure was calculated by the following formula: (OR-1)/OR. Percentages are rounded to the closest integer in the text and to the closest decimal in the tables; 95\% CI to OR are presented in parentheses in the text.

\section{Results}

Fourteen university hospitals and two regional general hospitals recruited cases. Among the 185 cases reported in 24 months, the parents of three children were not able to be contacted by telephone, and five secondarily declined the interview. The final data set included 177 patients aged 2 months to 16 years.

\section{Clinical features}

The proportion of children 2 months to 2 years old $(33 \%)$ reported was relatively more important than those of other age groups. Haematemesis was present in almost all children, with the exception of a few younger ones, and maelena was more frequent in the 2 months to 2 years age group (24\% vs. 9\%). Most patients $(80 \%)$ had undergone endoscopic examination, which showed difference in lesion location according to age: $37 \%$ of children in the youngest age group presented with gastric lesions and 52\% with oesophageal lesions and $65 \%$ and $23 \%$, respectively, in older children. Duodenal lesions were rare in all age groups. Clinical presentation was similar in girls and boys (data not shown). The treatment required was antiulcer and antacid drugs in $60 \%$ of children, transfusion in $11 \%$, miscellaneous in $18 \%$ and none in 21\% (Tables 1 and 2).

\section{Risk factors}

Thirty-three children had at least one medical risk factor of bleeding, such as previous medical history of portal hypertension, personal history of ulcer or UGIB, coagulation disorders or rheumatoid purpura. Details of medical risk factors are presented in Table 1. Among them, 21.2\% had also used an NSAID at some point during the 4 previous weeks, which is significantly different from the proportion of NSAID use in children without medical risk factor $(p=0.001)$.

In the 4-week period prior to bleeding, $79.1 \%$ of children had taken at least one drug. Eighty-three children $(46.9 \%)$ had taken at least one NSAID at some point during these 4 weeks, which was ibuprofen in $70 \%$ of cases, aspirin in $31 \%$ and another NSAID in $11 \%$ (Table 3). Other NSAIDs used were fenamate, ketoprofen, flurbiprofen and naproxen. This use had occurred mostly in the week at risk. The 3- to 7-year-old age group was the most exposed to NSAIDs. Fever was reported 69 times $(83 \%)$ as the reason for NSAID uses, moderate pain 18 times $(22 \%)$, rheumatic indication once $(1 \%)$ and reasons unknown 11 (13\%). NSAIDs dosages used were indeed mainly those corresponding to the recommended doses for antipyretic and analgesic treatments: $18.4 \pm 11 \mathrm{mg} / \mathrm{kg}$ per day for ibuprofen and $24 \pm 16 \mathrm{mg} / \mathrm{kg}$ per day for aspirin, $31.75 \pm 17 \mathrm{mg} / \mathrm{kg}$ per day for fenamates, $1.75 \pm 0.25 \mathrm{mg} / \mathrm{kg}$ per day for ketoprofen, $2 \mathrm{mg} / \mathrm{kg}$ per day for flurbiprofen and $11.5 \mathrm{mg} / \mathrm{kg}$ per day for naproxen. The mean duration of NSAID use in the 4 weeks prior to bleeding was short and in accordance with their indication (1.9 \pm 1.5 days); it 
Table 1 Patient gender and clinical features by age

\begin{tabular}{|c|c|c|c|c|}
\hline & \multicolumn{4}{|l|}{ Age groups } \\
\hline & $\begin{array}{l}2 \text { months to }<2 \text { years } \\
N=58(32.8 \%)\end{array}$ & $\begin{array}{l}>3 \text { years to }<7 \text { years } \\
N=60(33.9 \%)\end{array}$ & $\begin{array}{l}>7 \text { years to }<16 \text { years } \\
N=59(33.3 \%)\end{array}$ & $\begin{array}{l}\text { Total } \\
N=177\end{array}$ \\
\hline Girls & $39(67.3)$ & $36(60.0)$ & $33(56.0)$ & $108(61.0)$ \\
\hline \multicolumn{5}{|l|}{ Initial sign } \\
\hline Haematemesis & $54(93.1)$ & $58(96.7)$ & $59(100)$ & $171(96.6)$ \\
\hline Maelena & $14(24.1)$ & $6(10.0)$ & $5(8.5)$ & $25(14.1)$ \\
\hline Haemorrhage shock & $2(3.5)$ & $2(3.3)$ & $1(1.7)$ & $5(2.8)$ \\
\hline Transfusion requirements & $4(6.9)$ & $6(6.7)$ & $10(17.0)$ & $20(11.3)$ \\
\hline Hospitalisation & $42(72.4)$ & $46(76.7)$ & $49(83.0)$ & $136(77.4)$ \\
\hline \multicolumn{5}{|l|}{ Previous medical history } \\
\hline $\begin{array}{l}\text { Personal history of ulcer or of upper } \\
\text { gastrointestinal bleeding }\end{array}$ & $3(5.2)$ & $7(11.7)$ & $10(17.0)$ & $20(11.3)$ \\
\hline Portal hypertension & $4(6.9)$ & $3(5.0)$ & $3(5.0)$ & $10(5.7)$ \\
\hline $\begin{array}{l}\text { Other relevant previous medical history } \\
\text { (coagulation disorders, rheumatoid purpura, other) }\end{array}$ & $4(6.9)$ & $4(26.7)$ & $7(11.9)$ & $15(8.5)$ \\
\hline
\end{tabular}

varied from $1.6 \pm 1.4$ days for aspirin to $1.8 \pm 1.4$ for ibuprofen. Other drugs most frequently reported were paracetamol (37\%) and antibiotics (29\%).

Table 4 shows the crude and adjusted OR (with 95\% CI) for NSAIDs use during the risk and control periods in the 177 children studied, controlling for the most frequently used drugs. The adjusted OR of exposure to NSAIDs was 8.2 (2.6-26.0) for NSAIDs altogether, and this was 10.0 92.0-51.0) for ibuprofen and $7.3(0.9-59.4)$ for aspirin. The adjusted OR of exposure to NSAIDs related to oesophageal lesions was $1.0(0.2-7.2)$ and related to gastric or duodenal lesions 7.9 (1.7-37.5).
The OR for NSAID use and UGIB was 14.1 (2.8-71.2) and $3.4(0.6-21.3)$ in the 2 months to 7 years and 8 16 years age groups, respectively ( $p$ for trend $<0.001$ ).

\section{Discussion}

To our knowledge, this is the first published populationbased survey of UGIB in children that explores drug risk factors. Almost half (45\%) of the university hospitals of the country participated, plus two very large regional hospitals. Recruitment per centre was very close to plans

Table 2 Endoscopy findings (numbers are not exclusive)

\begin{tabular}{|c|c|c|c|c|}
\hline & $\begin{array}{l}2 \text { months to }<2 \text { years } N=58 \\
(32.8 \%)\end{array}$ & $\begin{array}{l}>3 \text { years to }<7 \text { years } N=60 \\
(33.9 \%)\end{array}$ & $\begin{array}{l}>7 \text { years to }<16 \text { years } N=59 \\
(33.3 \%)\end{array}$ & $\begin{array}{l}\text { Total } N=177 \\
(\%)\end{array}$ \\
\hline Endoscopy performed & $46(79.3)$ & $46(76.7)$ & $49(83.1)$ & $141(79.7)$ \\
\hline Endoscopy: normal & $8(17.4)$ & $11(23.9)$ & $5(10.2)$ & $24(17.0)$ \\
\hline Endoscopy: unknown & $2(4.3)$ & $1(2.2)$ & $1(2.0)$ & $4(2.8)$ \\
\hline Oesophageal lesions & $24(52.2)$ & $10(22.7)$ & $18(36.7)$ & $52(36.9)$ \\
\hline $\begin{array}{l}\text { - Erythematous } \\
\text { oesophagitis }\end{array}$ & 2 & 5 & 10 & 17 \\
\hline - Erosive oesophagitis & 5 & 2 & 5 & 12 \\
\hline - Ulcerated oesophagitis & 5 & 4 & 4 & 13 \\
\hline - Varices & 3 & 2 & 2 & 7 \\
\hline - Other & 3 & 0 & 5 & 8 \\
\hline Gastric lesions & $17(37.0)$ & $30(65.2)$ & $32(65.3)$ & $79(56.0)$ \\
\hline - Erythematous gastritis & 3 & 10 & 11 & 24 \\
\hline - Erosive gastritis & 4 & 3 & 5 & 12 \\
\hline - Ulcerations & 0 & 4 & 6 & \\
\hline
\end{tabular}


Table 3 Drugs used in the 4 weeks before bleeding, by age

\begin{tabular}{|c|c|c|c|c|}
\hline & \multicolumn{4}{|l|}{ Age groups } \\
\hline & $2 \mathrm{~m}$ to 2 years $N=58(32.8 \%)$ & 3to 7 years $N=60(33.9 \%)$ & 8to 16years $N=59(33.3 \%)$ & Total $N=177(\%)$ \\
\hline \multicolumn{5}{|l|}{ Drugs } \\
\hline - Any NSAIDs & 17 & 40 & 26 & $83(46.9)$ \\
\hline - Ibuprofen & 12 & 31 & 15 & $58(32.8)$ \\
\hline - Aspirin & 5 & 11 & 10 & $26(14.7)$ \\
\hline - Other NSAIDs ${ }^{\mathrm{a}}$ & 1 & 4 & 4 & $9(5.1)$ \\
\hline - Paracetamol & 17 & 28 & 20 & $65(36.7)$ \\
\hline - Antibiotics & 15 & 24 & 12 & $51(28.8)$ \\
\hline - Antacids and antiulcer & 23 & 7 & 10 & $40(22.6)$ \\
\hline - Other drugs & 29 & 27 & 22 & $78(44.1)$ \\
\hline
\end{tabular}

${ }^{\text {a }}$ Fenamates 6, ketoprofen 2, flurbiprofen 1 and naproxen 1. One child took two types of nonsteroidal anti-inflammatory drugs (NSAIDs)

( 5.5 vs. 6 cases per centre per year), and the study finally had the power to assess the risk associated with different risk factors and drugs by age, gender and clinical presentation. One case out of five occurred in patients with a medical risk factor or medical history, and $40 \%$ or more of the children had taken an NSAID in the week prior to hospitalisation, three quarters of which were ibuprofen. The frequency of children who took aspirin is not surprising, as in contrast to most European countries, aspirin is not contraindicated for use in children in France. In fact, only a caution of use is included in aspirin summary of product characteristics (SPC) in cases of viral infections (flu, chicken pox). In approximately two thirds of cases, no risk factor was found. Boys and girls had very similar presentations, and the risk seemed to decline with age. The results show, for the first time, that in children, as in adults, there is apparently no excess risk of oesophageal lesion associated with NSAIDS [10, 12-14]. According to the findings, there would be an increased risk of gastric lesions with these drugs, with no apparent difference between ibuprofen and aspirin, taken at analgesic or antipyretic doses. The study confirms that UGIB is rare, so that the absolute risk associated with these drugs may remain small altogether.

Before exploring these findings further, biases that may have participated to the observations are discussed. First, parents may better recall drug intake in their offspring in the week preceding hospitalisation than those that occurred several weeks earlier. The fact that, as expected, there was no increased risk associated with NSAIDs use observed in

Table 4 Crude and adjusted odds ratios (OR) and confidence intervals (CI) for the use of NSAIDs and other classes of drugs in the 4 weeks before bleeding in the 177 children included in the study

\begin{tabular}{|c|c|c|c|c|c|c|}
\hline Exposure & $\begin{array}{l}\text { Week } 1 \text { before } \\
\text { bleeding (at-risk) } N\end{array}$ & Percent & $\begin{array}{l}\text { Week } 4 \text { before } \\
\text { bleeding (control) } N\end{array}$ & Percent & $\begin{array}{l}\text { Crude OR } \\
(95 \% \mathrm{CI})\end{array}$ & $\begin{array}{l}\text { Adjusted } \mathrm{OR}^{\mathrm{b}} \\
(95 \% \mathrm{CI})\end{array}$ \\
\hline All NSAIDs & 73 & $41.2 \%$ & 8 & $4.5 \%$ & $17.3(6.3-47.3)$ & $8.2(2.6-26.0)$ \\
\hline Oesophageal lesions & 11 & $6.2 \%$ & 5 & $2.8 \%$ & $3.0(0.6-11.0)$ & $1.0(0.2-7.2)$ \\
\hline Gastric or duodenal lesions & 38 & $21.5 \%$ & 5 & $2.8 \%$ & $11.9(3.7-39.0)$ & $7.9(1.7-37.5)$ \\
\hline Ibuprofen & 50 & $28.2 \%$ & 5 & $2.8 \%$ & $23.5(5.7-96.7)$ & $10.0(2.0-51.0)$ \\
\hline Aspirin & 23 & $13.0 \%$ & 2 & $1.1 \%$ & $22.0(3.0-163)$ & $7.3(0.9-59.4)$ \\
\hline Other NSAIDs & 7 & $4.0 \%$ & 2 & $1.1 \%$ & $3.5(0.7-16.8)$ & $\mathrm{NC}$ \\
\hline $\begin{array}{l}\text { All NSAIDs in the } 2 \text { months } \\
\text { to } 7 \text { years }^{\mathrm{a}} \text { age group }\end{array}$ & 56 & $31.6 \%$ & 4 & $2.3 \%$ & $27.0(6.6-110)$ & $14.1(2.8-71.2)$ \\
\hline $\begin{array}{l}\text { All NSAIDs in the } 8 \text { to } 16 \text { years } \\
\text { age group }\end{array}$ & 17 & $9.6 \%$ & 4 & $2.3 \%$ & $7.5(1.7-32.8)$ & $3.4(0.6-21.3)$ \\
\hline
\end{tabular}

${ }^{\text {a }}$ The 2 months to 2 years and 3- to 7-years age groups were aggregated due to small numbers

${ }^{\mathrm{b}}$ OR were adjusted for the use of paracetamol, corticosteroids, antibiotics, antacids and antiulcer; an adjusted model was applied separately for each drug or group of drugs studied

$N C$ not calculated due to small numbers 
children with oesophageal lesions $(\mathrm{OR}=1.0)$ militates against an important recall bias, as parents would not know this difference. Also, there was no significant change observed in the risk estimates when a more recent time window (week 3) was used as control (data not shown). Second, physicians may be more likely to diagnose UGIB in children exposed to NSAIDs: endoscopic examination was slightly less frequently performed in children exposed to NSAIDs than in non-NSAIDs users $(72 \%$ vs. $84 \%$, respectively), but NSAIDs users were diagnosed with severe signs as frequently as nonusers (63\% vs. $66 \%$, respectively); the OR for NSAIDs use in children who had undergone confirmatory endoscopy were similar to those observed in the sample as a whole: $7.7(2.1-28.0)$ vs. 8.2 (2.6-26.0), respectively. Third, the notoriety of the risk of UGIB side effects of NSAIDs may have inclined centres to more frequently report cases recently exposed to NSAIDs than those that were not. Important efforts were made to minimize this bias by insisting very frequently on the necessity to report all cases of UGIB observed. The average number of cases reported by centre and per year $(n=5.5)$ over the study period was very close to the number planned before the study started $(n=6)$, and there was no significant variation in the percentage of exposure recorded per centre. All in all, we believe that the results are not likely to be explained fully by these biases. The case-crossover design has the advantage of controlling efficiently for nontransient individual confounders, such as genetic, biological or environmental factors, and has been shown to be efficient in pharmacoepidemiology [15-17].

Within the NSAIDs category, the risk was similar for ibuprofen, aspirin or all NSAIDs (adjusted OR 10.0, 7.3 and 8.2, respectively). There was not sufficient use of other NSAIDs to conclude on their risks individually, but one cannot exclude the possibility that others may be risk factors also. However, as they represented a small fraction of drugs used, the risk for all NSAIDs reflect mainly that of ibuprofen and aspirin. These results are not inconsistent with the few data published on NSAIDs and UGIB in children mentioned in the "Introduction". Indeed, in a published series of 231 children who underwent endoscopy for UGIB, 15\% took NSAIDs [6]; from an Australian hospital adverse drug reactions database, four haematemesis with NSAIDs were collected over 5 years, three of which were associated with ibuprofen (used at the higher end of the usual range of dose) and one with celecoxib at too high a dose [8]. The only randomised trial is the Lesko study [9], which reported more cases of UGIB with ibuprofen than with paracetamol (four vs. zero cases) but may have lacked power (although its sample size was large).

The RR estimated here with NSAIDs use seems higher than that usually observed in adults (eight vs. two to four).
This may be due to chance or to the fact that children may have a higher sensitivity to NSAIDs side effects. Alternative explanations may be that primary exposure to the drugs may be associated with higher risk, which is the case in adults [18], or to the so-called depletion of susceptible effect that we previously demonstrated to occur with NSAIDs and UGIB in adults [19] (people at risk tend to be withdrawn from the opportunity to exposure and to subsequently develop disease more and more with time). The number of cases reported in the younger age groups was indeed proportionally much higher than in older children. The fact that younger patients may be more readily hospitalised in the presence of bleeding is not supported by the similar severity and percentage of confirmed lesions between age groups. The study confirms that the number of UGIB seen in paediatric units of university or regional hospitals is few (one case every other month). Not all cases of this disease are referred to these hospitals, as some may be seen in general hospitals without paediatric units. Typically, nonuniversity or nonregional general hospitals accrue a lesser number of cases per year. Using the numbers observed and applying different hypothesis yields estimates between 1,000 and 2,000 cases per year in France, which is an incidence in the vicinity of 1-2 per 10,000 children per year in the 2 months to 16 years old age group $(12,000,000$ in the country). According to this study, the fraction of cases attributable to NSAIDs would be $88 \%$ of the $41 \%$ exposed in the week before occurrence, which is $36 \%$.

To conclude, this study confirms that UGIB is rare, occurs more likely in children of younger age and shows that it is attributable to the use of NSAIDs, including ibuprofen and aspirin, in approximately one third of cases. Some of these cases may be avoided by using alternative drugs such as paracetamol for analgesic or antipyretic purposes, particularly in patients with medical risk factors for the disease. The findings from this study call for more caution in prescribing NSAIDs to children.

Acknowledgements The authors thank Richard Medeiros (Rouen University Hospital Medical Editor) for editing the manuscript.

Funds This study was supported by research grants from the French Agency of Medical Security of Health Products (AFSSAPS).

Conflict of interest statements None of the authors have financial or personal relationships, academic competition or intellectual commitments that might bias the work or interfere with objective judgment.

Access to data Lamiae Grimaldi-Bensouda, Elisabeth Autret-Leca and Benoit David had full access to all data in the study and take responsibility for the integrity of the data and the accuracy of the data analysis. 


\section{References}

1. Laine L (2004) Proton pump inhibitor co-therapy with nonsteroidal anti-inflammatory drugs-nice or necessary? Rev Gastroenterol Disord 4(Suppl 4):S33-S41

2. Van Leerdam ME (2008) Epidemiology of acute upper gastrointestinal bleeding. Best Pract Res Clin Gastroenterol 22(2):209-224

3. Hollenz M, Stolte M, Leodolter A, Labenz J (2006) NSAIDassociated dyspepsia and ulcers: a prospective cohort study in primary care. Dig Dis 24(1-2):189-194

4. Cagnoni PJ, Aledort L (1994) Gastrointestinal bleeding in hemophilia as a complication of the use of over the counter non-steroidal anti-inflammatory drugs. Am J Hematol 47:336-337

5. Fox VL (2000) Gastrointestinal bleeding in infancy and childhood. Gastroenterol Clin North Am 29(1):37-66

6. Mouterde O, Hadji S, Mallet E, Le Luyer B, Metayer P (1996) Les hémorragies digestives chez l'enfant, à propos de 485 endoscopies. Ann Pédiatr 43:167-176

7. Keenan GF, Giannini EH, Athreya BH (1995) Clinically significant gastropathy associated with nonsteroidal antiinflammatory drug use in children with juvenile rheumatoid arthritis. J Rheumatol 22(6):1149-1151

8. Titchen T, Cranswick N, Beggs S (2005) Adverse drug reactions to nonsteroidal anti-inflammatory drugs, COX-2 inhibitors and paracetamol in a paediatric hospital. Br J Clin Pharmacol 59 (6):718-723

9. Lesko SM, Mitchell AA (1995) An assessment of the safety of pediatric ibuprofen. A practitioner-based randomized clinical trial. JAMA 273(12):929-933

10. Garcia Rodriguez LA, Hernandez-Diaz S (2001) Relative risk of upper gastrointestinal complications among users of acetaminophen and nonsteroïdal anti-inflammatory drugs. Epidemiology 12 (5):570-576
11. Maclure M (1991) The case-crossover design: a method for studying transient effects on the risk of acute events. Am J Epidemiol 133(2):144-153

12. Holvoet J, Terriere L, Van Hee W, Verbist L, Fierens E, Hautekeete ML (1191) Relation of uppergastrointestinal bleeding to non-steroidal anti-inflammatory drugs and aspirin: a casecontrol study. Gut 32(7):730-734

13. Laporte JR, Ibanez L, Vidal X, Vendrell L, Leone R (2004) Upper gastrointestinal bleeding associated with the use of NSAIDs: newer versus older agents. Drug Saf 27(6):411-420

14. Gutthann SP, Garcia Rodriguez LA, Raiford DS (1997) Individual non-steroidal anti-inflammatory drugs and other risk factors for upper gastrointestinal bleeding and perforation. Epidemiology 8 (1):18-24

15. DeStefano F, Verstraeten T, Jackson LA, Okoro CA, Benson P, Black SB, Shinefield HR, Mullooly JP, Likosky W, Chen RT (2003) Vaccinations and risk of central nervous system demyelinating diseases in adults. Arch Neurol 60:504-509

16. Viboud C, Boëlle PY, Kelly J, Auquier A, Schlingmann J, Roujeau JC, Flahault A (2001) Comparison of the statistical efficiency of case-crossover and case-control designs: Application to severe cutaneous adverse reactions. J Clin Epidemiol 54:12181227

17. Etienney I, Beaugerie L, Viboud C, Flahault A (2003) Nonsteroidal anti-inflammatory drugs as a risk factor for acute diarrhoea: a case crossover study. Gut 52:260-263

18. Levy M, Miller DR, Kaufman DW, Siskind V, Schwingl P, Rosenberg L, Strom B, Shapiro S (1988) Major upper gastrointestinal tract bleeding. Relation to the use of aspirin and other nonnarcotic analgesics. Arch Intern Med 148(2):281285

19. Moride Y, Abenhaim L (1994) Evidence of the depletion of susceptibles effect in non-experimental pharmacoepidemiologic research. J Clin Epidemiol 47(7):731-737 